\title{
OPPOSITES FIT:
}

\section{REGULATORY FOCUS COMPLEMENTARITY AND RELATIONSHIP WELL-BEING}

\author{
Vanessa K. Bohns \\ University of Waterloo, Waterloo, ON, Canada \\ Gale M. Lucas \\ Western Oregon University \\ Daniel C. Molden and Eli J. Finkel \\ Northwestern University \\ Michael K. Coolsen \\ Shippensburg University \\ Madoka K. Kumashiro \\ Goldsmiths, University of London \\ Caryl E. Rusbult \\ Vrije Universiteit, Amsterdam, The Netherlands \\ E. Tory Higgins \\ Columbia University
}

\begin{abstract}
Two studies of romantic couples examined the circumstances under which complementary goal-pursuit strategies (specifically, the pairing of a relationship partner who prefers to pursue goals eagerly with a relationship partner who prefers to pursue goals vigilantly) lead to positive relationship outcomes. As hypothesized, couples who reported higher levels of goal congruence (Study 1) or greater self-other overlap (Study 2) benefited from complementary regulatory focus orientations. We suggest that such benefits stem from the advantages provided by the availability of both eager and vigilant strategic preferences, which allow complementary couples to "divide and conquer" goal pursuits as a unit so that both relationship part-
\end{abstract}

The research reported in this article was supported by the following grants: NSF 719780 to Eli J. Finkel, NIMH 39429 to E. Tory Higgins, and NSF BCS-0951571 to Daniel C. Molden.

Address correspondence to Vanessa K. Bohns, Department of Management Sciences, University of Waterloo, 200 University Avenue West, Waterloo, Ontario, Canada N2L 3G1; E-mail: vbohnse? uwaterloo.ca.

Q 2013 Guilford Publications, Inc. 
ners can take on their preferred eager or vigilant strategic role. We further suggest that goal congruence is necessary to capitalize on these proposed advantages of complementary eager or vigilant goal-pursuit strategies.

Many goals in life are pursued not alone, but in tandem with other people. Yet, while individual goal pursuit has been studied extensively, relatively little is known about joint goal pursuit. Researchers have only recently begun to study how the dynamics of joint goal-pursuit might operate, focusing primarily on how these dynamics affect task outcomes (e.g., Mauro, Pierro, Mannetti, Higgins, \& Kruglanski, 2009). Even less research has addressed how joint goal pursuit may also affect the relationship between the individuals involved (for an exception see Gere, Schimmack, Pinkus, \& Lockwood, 2011).

We explore the effect on relationship well-being of complementary goal-pursuit strategies-specifically, regulatory focus orientations-within couples. When two people merge their lives in a romantic partnership, they establish a shared mode of goal pursuit where they must coordinate their actions to achieve joint goals. Despite the volumes of research showing that similarity between partners benefits relationships, we explore whether complementary goal pursuit strategies predict relationship well-being. Specifically, we argue that regulatory focus complementarity allows a couple to simultaneously implement both eager and vigilant selfregulatory strategies during goal pursuit, thereby increasing the likelihood that each relationship partner pursues goals in a manner that is most comfortable to him or her. However, we further stipulate that such complementarity should primarily be beneficial to the extent that the two individual members of the couple do, in fact, conceptualize their goal pursuit as a joint effort. Such goal congruence would allow couples to capitalize on the advantages of each individual's means of goal pursuit, while avoiding the potential for conflict that may also come with preferring different goal-pursuit strategies.

\section{JOINT GOAL PURSUIT AND RELATIONSHIP WELL-BEING}

For effective goal pursuit, individuals typically need to be able to access multiple goal-pursuit strategies and effectively switch between them (Fishbach \& Ferguson, 2007). For example, an individual may need to be fast in one situation, but accurate in another. Moreover, in some situations, for instance, a typical signal detection exercise, it may be necessary for an individual to use more than one strategy at the same time, that is, be both fast and accurate (Bogacz, Brown, Moehlis, Holmes, \& Cohen, 2006). Yet most individuals are better at, or have a preference for using, one type of strategy over another. Furthermore, there is often a cost to switching between strategies (Hamilton, Vohs, Sellier, \& Meyvis, 2010). For these reasons, joint goal-pursuit with someone who has complementary strategic preferences could prove advantageous. Having a partner with a complementary strategic preference allows both members of a dyad to delegate their non-preferred strategy to their partner, in turn allowing each individual to adopt his or her preferred regulatory strategy while still being prepared for a range of responses as a unit. 
Previous research has demonstrated that this kind of strategic-role delegation occurs spontaneously in joint goal-pursuit. Research on social compensation has shown that when engaged in a joint task, people adjust their behavior in light of their assessment of an interaction partner's strategic inclinations. Plaks and Higgins (2000) found that when the strategic orientation of a participant's interaction partner matched the requirements of a task, participants engaged in social loafing. However, when their interaction partner's strategic orientation did not match the task, participants worked harder to compensate for the strategic shortcomings of their partner. Similar dynamics have been shown to operate in close relationships. Research on transactive memory has demonstrated that a comparable delegation of roles occurs between long-term relationship partners working on joint memory tasks (Wegner, Erber, \& Raymond, 1991). Relationship partners have also been shown to engage in a transactive form of self-regulation where each partner "outsources" certain aspects of self-regulation to the other (Fitzsimons \& Finkel, 2011). Thus, it seems that during joint goal pursuit two people will indeed anticipate (whether consciously or unconsciously) the need for a division of strategic roles and behave accordingly.

This strategic "division of labor" may be facilitated by complementarity in relationship partners' strategic preferences. For example, Bohns and Higgins (2011) previously demonstrated that individuals prefer an interaction partner with complementary strategic preferences for tasks that can be "divided and conquered." However, Bohns and Higgins looked only at interaction partner preferences, rather than actual relationship outcomes. Here we propose that the role specialization that results from such complementarity in close relationships should lead to greater overall satisfaction with one's relationship.

When individuals act in line with their own strategic preferences, they experience positive affect (Moskowitz \& Cote, 1995) and regulatory fit (Higgins, 2000) a "feeling of rightness" about what they are doing. Moskowitz and Cote (1995) found that individuals who scored high on trait measures of agreeableness, quarrelsomeness, or dominance experienced greater positive affect when they were able to behave in their preferred agreeable, quarrelsome, or dominant manner. Similarly, research on regulatory fit finds that when individuals engage in a task using their preferred strategic manner, they enjoy what they are doing more, are more strongly engaged, and assign greater value to the outcomes they experience (Cesario, Grant, \& Higgins, 2004; Freitas \& Higgins, 2002; Higgins, Idson, Freitas, Spiegel, \& Molden, 2003). When couples have complementary strategic preferences and are able to divide joint tasks in ways that allow each of them to behave in their preferred manner, the increased positive affect, engagement, and value they experience may lead to increased satisfaction with the relationship as a whole.

In the current research, we tested the benefits of complementary strategic preferences on relationship well-being using individuals' regulatory focus. Regulatory focus theory describes two basic orientations toward goal pursuit a promotion orientation focused on growth and advancement and a prevention orientation focused on security and responsibility (Higgins, 1997). Although everyone values both growth and security, people display chronic individual differences in whether they tend to be predominantly focused on either promotion or prevention (Higgins et al., 2001). Consistent with their greater concern with advancement, individuals who are promotion-focused prefer eager strategies of goal-pursuit. In contrast, consistent with their greater concern with security, individuals who are prevention- 
focused prefer vigilant strategies of goal-pursuit (Molden, 2012; Molden, Lee, \& Higgins, 2008). ${ }^{1}$

Many goals that couples encounter in their daily lives require both eagerness and vigilance. Childrearing, for example, requires both nurturance (eagerly encouraging the child to develop the ability to kick a soccer ball) and safety (vigilantly ensuring the child does not chase the ball into the street). If both relationship partners prefer to take on the eager role either the child's security needs will not be adequately met, or alternatively, the parent who is forced to adopt the vigilant role will be unhappy. Thus, complementarity could be beneficial by allowing the predominantly promotion-focused partner to take the eager role while the prevention-focused partner could take the vigilant role, leading to greater relationship satisfaction for both individuals.

\section{THE IMPORTANCE OF GOAL CONGRUENCE}

We have thus far outlined the potential benefits of complementary strategic preferences in close relationships. However, complementarity may also present problems-namely, differences in strategic preferences between two individuals can increase the potential for conflict and disagreement that cancel out any other benefits. For these reasons, we hypothesize that strategic complementarity will only predict relationship well-being when a couple is generally in agreement regarding their mutual goals and have a strong commitment to joint goal-pursuit-that is, when they exhibit high goal congruence.

The distinction we are proposing between the advantages and disadvantages of complementarity mirrors a distinction previously made in the close relationships literature between interpersonal conflict and interpersonal coordination (Finkel et al., 2006). An example of interpersonal conflict would be a scenario in which a couple has opposing preferences for where they would like to spend their summer vacation (e.g., John wants to go on an exciting, adventurous safari in Kenya and Mary prefers a safe, relaxing trip in Hawaii). Alternatively, an example of a coordination problem would be a scenario in which both members of the couple share the same preference (i.e., both John and Mary want to go on safari in Kenya) but must now figure out how to work together to pursue this preference (Rusbult \& Van Lange, 2003).

The process of strategic role division for which complementarity should be beneficial requires interpersonal coordination-it involves two individuals coordinating their actions and negotiating how they will pursue a particular goal or set of life goals (Bohns \& Higgins, 2011). However, before two individuals ever reach this coordination phase, they must first agree on what goals are important for them to pursue. For establishing such agreement, complementarity may increase the potential for conflict. Thus, we hypothesize that the benefits of complementarity will

1. Note that promotion and prevention orientations are not equivalent to approach and avoidance motivations (see Molden et al., 2008; Molden \& Winterheld,in press). Promotion-eager and

prevention-vigilant strategies can each be used as a means of either approaching desired end-states or avoiding undesired end-states. However, because approach and avoidance motivations are another important area of interest for relationship researchers (e.g., Gable, 2006; Impett, Strachman, Finkel, \& Gable, 2008), future research may benefit from exploring whether a focus on joint approach goals versus joint avoidance goals may moderate some of the effects proposed in the current research 
only emerge for couples that exhibit a high degree of congruence in their joint goal pursuit, which may reflect either agreement about joint goals or a commitment to shared goal pursuit (Gere et al., 2011). To return to our child-rearing example, complementarity should only be beneficial provided that the two parents are of one mind regarding what they want for their child (e.g., both parents want their child to succeed in soccer and avoid injury).

In our studies, we operationalized goal congruence in two different ways. In Study 1, we created a novel, face-valid measure of goal congruence. In Study 2, we used an established measure that is both theoretically and empirically associated with goal congruence: Inclusion of the Other in the Self (IOS; Aron, Aron, \& Smollan, 1992). In both studies, we hypothesized that only couples reporting high levels of goal congruence would exhibit the proposed benefits of complementarity.

\section{STUDY 1}

As our first test of this hypothesis, we constructed a goal-congruence scale to measure the extent to which a couple perceived that they shared the same joint goals. We assessed each partner's chronic regulatory focus and examined whether the relationship between the partners' regulatory focus orientations interacted with goal congruence to predict relationship well-being. We hypothesized that complementary regulatory focus orientations within couples would be associated with higher relationship well-being under conditions of high goal congruence, but not under conditions of low goal congruence.

\section{PROCEDURE}

Fifty-one dating couples participated for $\$ 35$ compensation. Participants' average age was 20.5 years and $67 \%$ were Caucasian. The couples had been dating for an average of 16.15 months (range $=3$ to 41 months, $S D=10.64$ ) Participants completed a series of online questionnaires during which they reported their promotionfocused and prevention-focused tendencies, self-esteem, and relationship wellbeing. Ten days later, participants attended a laboratory session and completed our goal-congruence measure. Participants completed all measures independent of their partners.

Regulatory Focus Measure. We assessed regulatory focus with the Regulatory Focus Questionnaire (RFQ; Higgins et al,, 2001). The RFQ is an 11-item measure where participants rate their agreement with promotion and prevention statements on 1 to 7 Likert-type scales (Higgins et al., 2001). A sample promotion item is, "How often have you accomplished things that have gotten you 'psyched' to work even harder?" A sample prevention item is, "Not being careful enough has gotten me into trouble at times" (reversed-scored). Six items comprise the promotion subscale $(\mathrm{a}=.72 ; M=3.66$; Range $=3-7 ; S D=.67)$, and five items comprise the prevention subscale $(\mathrm{a}=, 84 ; M=3.38$; Range $=1.4-7 ; \mathrm{SD}=.85)$.

Although people can vary in the strength of both their promotion and prevention motivations, in the current research we are interested in our participants' predominant focus on one motivational orientation over the other. In everyday life, 
individuals constantly encounter situations in which they must decide whether to adopt an eager or a vigilant strategy. For example, when driving a person cannot simultaneously apply the brakes when a traffic light turns yellow (a vigilant strategy) and try to beat the light by stepping on the accelerator (an eager strategy). While individuals may have varying levels of both eager and vigilant inclinations in these situations, it is the relative strength of these inclinations that will ultimately decide how they behave. Thus, whatever people's level of promotionfocused eagerness, if they possess a higher level of prevention-focused vigilance, they would experience greater regulatory fit from adopting a vigilant strategy of stopping at the yellow light than they would by adopting an eager strategy of accelerating through it. As our measure of this relative preference for a particular strategy, we calculated an index of participants' predominant regulatory focus by subtracting the prevention subscale from the promotion subscale of the RFQ. This index has served as a standard measure of predominant regulatory focus in numerous published studies (e.g., Bohns \& Higgins, 2011; Cesario, Grant, \& Higgins, 2004; Higgins et al., 2001; Hong \& Lee, 2008).

Relationship Well-Being. Three relationship well-being measures were included in the current study: satisfaction (Rusbult et al., 1998; $\alpha=.88$ ), commitment (Rusbult et al., 1988; $\alpha=.94$ ), and trust (Fletcher, Simpson, \& Thomas, 2000; $\alpha=.90$ ). Satisfaction concerns the extent to which people feel their needs and desires for the relationship are being met; commitment is related to an individual's intent to continue a relationship; trust reflects the extent to which an individual believes his or her partner will be responsive to his or her needs. Our primary dependent variable is a combined scale of the standardized scores of all three variables (a measure of overall relationship well-being; $\mathrm{a}=.80$ ).

Goal Congruence Measure. To measure goal congruence, we developed a short, face-valid, 5 -item measure ( $\alpha=.90$; see Table 1$)$. These scale items capture both of the components of goal congruence that we have identified (Gere et al., 2011): agreement about joint goals, and a commitment to shared goal pursuit. The high

reliability of our goal congruence scale suggests that these two aspects of goal congruence are empirically highly related.

Additional Measure. Since self-esteem has been positively associated with both relationship well-being (Murray, Holmes, \& Griffin, 2000) and a promotion focus (Higgins, 2008) in previous research, we also assessed participants' self-esteem (Rosenberg, $1965 ; \alpha=.90$ ).

\section{RESULTS AND DISCUSSION}

We predicted that when goal congruence among couples was high, complementarity in couples' regulatory focus orientations would be associated with greater relationship well-being, but the same would not be true when goal congruence was low. These results would be indicated by a three-way interaction of self regulatory focus $\times$ partner regulatory focus $\times$ goal congruence predicting relationship well-being. In both studies, we used multilevel modeling for our analyses (Kenny, Kashy, \& Bolger, 1998; Raudenbush \& Bryk, 2002). Multilevel modeling accounts for the non-independent data that exists when studying couples by modeling vari- 
TABLE 1.
1. I feel like my partner and $t$ are "on the same page" in terms of the goals we pursue together.
2. When it comes to pursuing goals as a couple, I feel like my partner and I are "of one mind."
3. I'm confident that my partner and I generally share the same goals for our relationship.
4. Sometimes I feel like my goals are incompatible with my partner's goals. (reversed)
5. Making decisions with my partner can be difficult because we have very different goals. (reversed)

ance at both the lower level (within-couple) and the higher level (across-couple) simultaneously. Because there were no gender differences in Studies 1 or 2, it was not necessary to conduct these analyses using distinguishable dyads.

We first entered the main effects of goal congruence, participants' own regulatory focus, and their partners' regulatory focus on relationship well-being, followed by terms representing all possible two-way interactions in a second step, and then a term representing the three-way interaction of self regulatory focus $x$ partner regulatory focus $\times$ goal congruence in a third step. Because predominant promotion focus was positively associated with self-esteem, $\beta=.24, t(90)=3.47, p$ $=.001$, self-esteem was included as a covariate in the analyses.

There were no main effects of goal congruence, self or partner regulatory focus, or self-esteem on relationship well-being, and no significant two-way interactions. However, as predicted, the three-way interaction term of self regulatory focus $\times$ partner regulatory focus $\times$ goal congruence predicting relationship well-being was (marginally) significant, $\beta=-.14, t(41)=-1.93, p=.06$. To illuminate the nature of the three-way interaction, simple slope tests were conducted at $1 S D$ above (indicating high goal congruence) and at $1 S D$ below (indicating low goal congruence) mean goal congruence. For couples with high goal congruence, the interaction term of self regulatory focus $\times$ partner regulatory focus was significantly negative, $\beta=-.28, t(41)=-2.39, p=.02$, indicating a beneficial effect of complementarity for relationship well-being. However, for couples with low goal congruence, the self regulatory focus $\times$ partner regulatory focus interaction term was nonsignificant, $\beta$ $<.001, t(41)<1.00$, indicating that complementarity did not predict relationship well-being (Figure 1).

\section{STUDY 2}

In Study 1, we constructed a novel measure of goal congruence and found that complementarity predicted relationship well-being in a sample of dating couples only under conditions of high goal congruence. In Study 2, we sought to replicate these results in a sample of married couples using a measure that has already been established in the close relationships literature. We identified a measure that should theoretically be related to the construct of goal congruence: perceived selfother overlap as measured by the "Inclusion of Other in Self" (IOS) scale (Aron, Aron, \& Smollan, 1992).

Including another person in one's own self-concept involves adopting that person's interests, traits, and qualities as one's own. It should similarly entail adopt- 

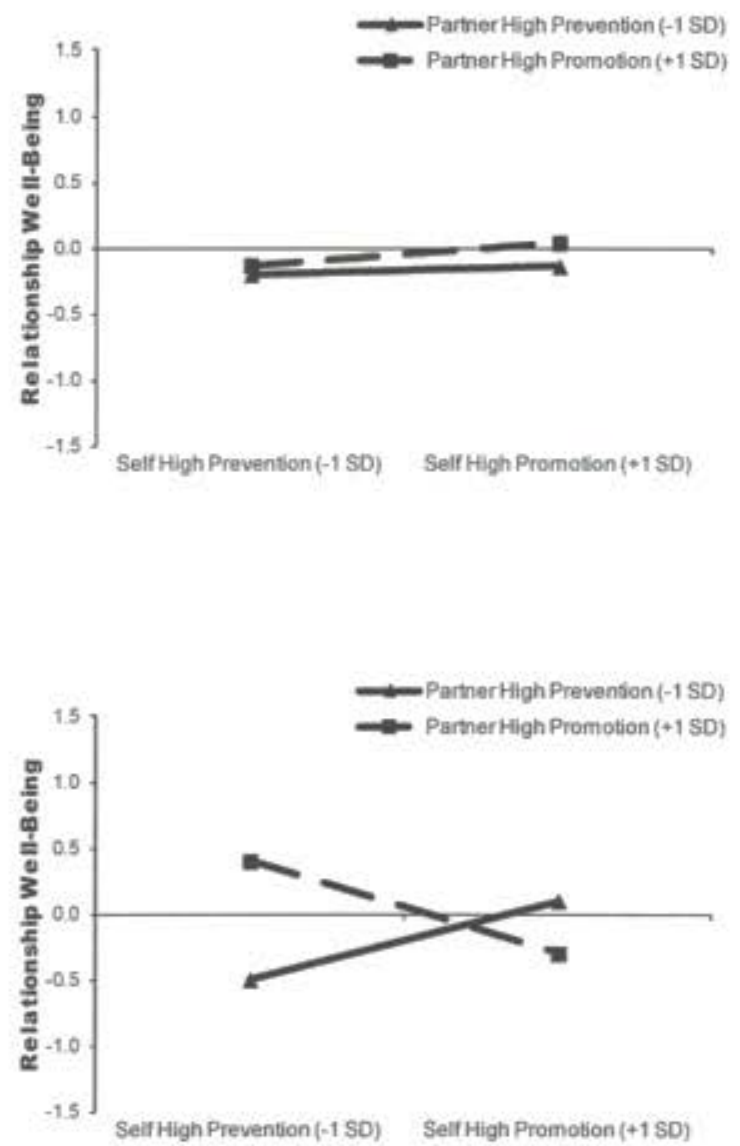

FIGURE 1. The effect of self-regulatory focus $x$ partner regulatory focus on relationship wellbeing under conditions of low goal congruence (-1 SD; Panel A) vs. high goal congruence i+ $1 S D$; Panel B) in Study 1.

ing that person's goal pursuits as one's own. Thus, self-other overlap should be positively associated with goal congruence. In support of this point, the founders of self-expansion theory have stated that partners with high self-other overlap should experience the pursuit and attainment of one another's goals as their own: "[F]or example, helping other is helping self; interfering with other is interfering with self" (e.g., "I'll be quiet while Peter reads the instructions"; Aron, McLaughlin-Volpe, Mashek, Lewandowski, Wright, \& Aron, 2004, p. 105). Rather than take this theoretical association at face value, however, we report a pilot study below in which we tested this association between IOS and goal congruence empirically.

Finally, in addition to a measure of self-other overlap, a measure of dominance was also included in this study. Dominance is a domain in which complementarity effects have been extensively demonstrated in previous research Đreyer \& Horowitz, 1997. Tiedens \& Fragale, 2003). Thus, we controlled for interpersonal were independent of dominance effects. 


\section{PROCEDURE}

Forty-three married couples $(N=86)$ participated for $\$ 40$ compensation. Participants' average age was 43.01 years and $71.8 \%$ were Caucasian. The couples had been married for an average of 89.88 months (range $=1$ to 252 months, $S D=84.78$ ). Interested participants responded to online ads by e-mailing the experimenter with contact information for themselves and their partner. Separate e-mails with a link to an online questionnaire were then sent to each spouse.

Regulatory Focus Measure. We used the same regulatory focus questionnaire from Study 1 (Higgins et al., 2001; promotion subscale: $a=.72 ; M=5.42$; Range $=1.5-5$; $S D=.79$; prevention subscale: $a=.84 ; M=4.46$; Range $=1.6-5 ; S D=1.22$ ).

Relationship Well-Being. As in Study 1, our relationship well-being measures included satisfaction (Rusbult, Martz, \& Agnew, 1998; $\alpha=.93$ ) and trust (Rempel, Holmes, \& Zanna, 1985; $\alpha=.87$ ). This study did not include a measure of commitment, but we also included a measure of dyadic adjustment (Spanier, 1976; $\alpha=$ .77), which assesses several broad qualities of couple well-being (e.g., affection, intimacy). The internal consistency of our relationship well-being index of all three variables was $\mathrm{a}=.85$.

IOS Scale. To measure goal congruence, we used the Inclusion of Other in the Self (IOS) scale developed by Aron, Aron, and Smollan (1992). The standard IOS scale is a single-item pictorial measure in which participants indicate from a series of seven increasingly overlapping circles the image that best depicts their relationship. Higher levels of self-other overlap are indicated by greater physical overlap between the circles.

As mentioned earlier, including another person in one's own self-concept involves adopting that person's interests, traits, and qualities as one's own, and one adoptable characteristic is that person's goals. However, goals remain only a single component of self-other overlap-someone may accept or reject another person's hobbies, talents, and personality traits for oneself, independent of that individual's goals. Therefore, although goal congruence should theoretically be associated with self-other overlap, the correspondence is not absolute.

Pilot Study. To test the degree of association between goal congruence and the IOS scale empirically, a sample of 101 participants ( 73 female) completed a webbased questionnaire. Participants were asked to think of either a current or a past relationship and then respond to a series of questions concerning that relationship. These questions included the IOS scale (Aron, Aron, \& Smollan, 1992) and our goal congruence measure from Study 1 . Analyses indicated that our goal congruence measure again had good internal reliability $(\alpha=.81)$. Moreover, as predicted, our goal congruence measure was positively correlated with the IOS scale, $r(97)=.51$, $p<.001$. These findings support the theoretical argument that higher self-other overlap is associated with stronger goal congruence, even if the correlation is not perfect.

Additional Measures. We also included six items from the "Trait Dominance-Submissiveness Scale" (Mehrabian \& Hines, 1978; $\alpha=.66$ ). This scale asks participants to indicate the extent to which they agree with items related to dominant and submissive interpersonal styles (e.g., "I usually win arguments"). A measure of 
self-esteem (Rosenberg, $1965 ; \alpha=.93$ ) was again administered and included in all analyses.

\section{RESULTS AND DISCUSSION}

Consistent with our goal congruence hypothesis, we predicted that when selfother overlap was high (but not low), complementarity in couples' regulatory focus orientations would be associated with greater relationship well-being. These results would be indicated by a three-way interaction of self regulatory focus $x$ partner regulatory focus $\times$ self-other overlap.

As in Study 1, predominant promotion focus was associated with self-esteem, $\beta$ $=.39, t(43)=3.84, p<.001$. A significant association was also found between predominant promotion focus and dominance, $\beta=.27, t(42)=2.99, p=.005$. Both of these variables were included as covariates in our analyses.

Consistent with previous research, we found a positive main effect of self-esteem on relationship well-being, $\beta=.12, t(39)=2.06, p=.05$. Also consistent with previous research (Aron, Aron, \& Smollan, 1992), we found a positive main effect of perceived self-other overlap on relationship well-being, $\beta=.48, t(39)=6.23, p<.001$. There was also a positive main effect of dominance on relationship well-being, $\beta=$ $.17, t(39)=2.94, p=.005$. There were no significant main effects of self regulatory focus or partner regulatory focus and no significant two-way interactions.

As predicted, there was a significant three-way interaction of self regulatory focus $\times$ partner regulatory focus $\times$ self-other overlap, $\beta=-.13, t(36)=-2.07, p=$ .05 . To investigate the nature of the three-way interaction, simple slope tests were conducted at $1 S D$ above and at $1 S D$ below mean self-other overlap. For couples reporting high perceived self-other overlap, the self regulatory focus $\times$ partner regulatory focus interaction term was significantly negative, $\beta=-.25, t(36)=-2.44$, $p=.02$, indicating a beneficial effect of complementarity on relationship well-being. However, for couples reporting low perceived self-other overlap, there was no effect of complementarity, $\beta<.01, t(36)<1.00, p>.50$ (Figure 2).

\section{DISCUSSION}

In two studies, complementary strategic preferences led to greater relationship well-being for couples with relatively high levels of goal congruence. In Study 1 , couples with complementary regulatory focus orientations who reported greater goal congruence also reported greater relationship well-being, but this was not the case for couples reporting lower levels of goal congruence. In Study 2, regulatory focus complementarity predicted relationship well-being for couples who reported relatively high perceptions of self-other overlap; however, this pattern was not observed for those reporting low perceptions of self-other overlap. The results across the two studies, which were strikingly consistent (compare Figures 1 and 2), support our proposal that goal congruence is important for allowing the benefits of complementary strategic preferences to emerge.

We have argued that such benefits result from the role specialization and consequent regulatory fit that can be achieved when two relationship partners have complementary strategic preferences. This interpretation is consistent with previ- 

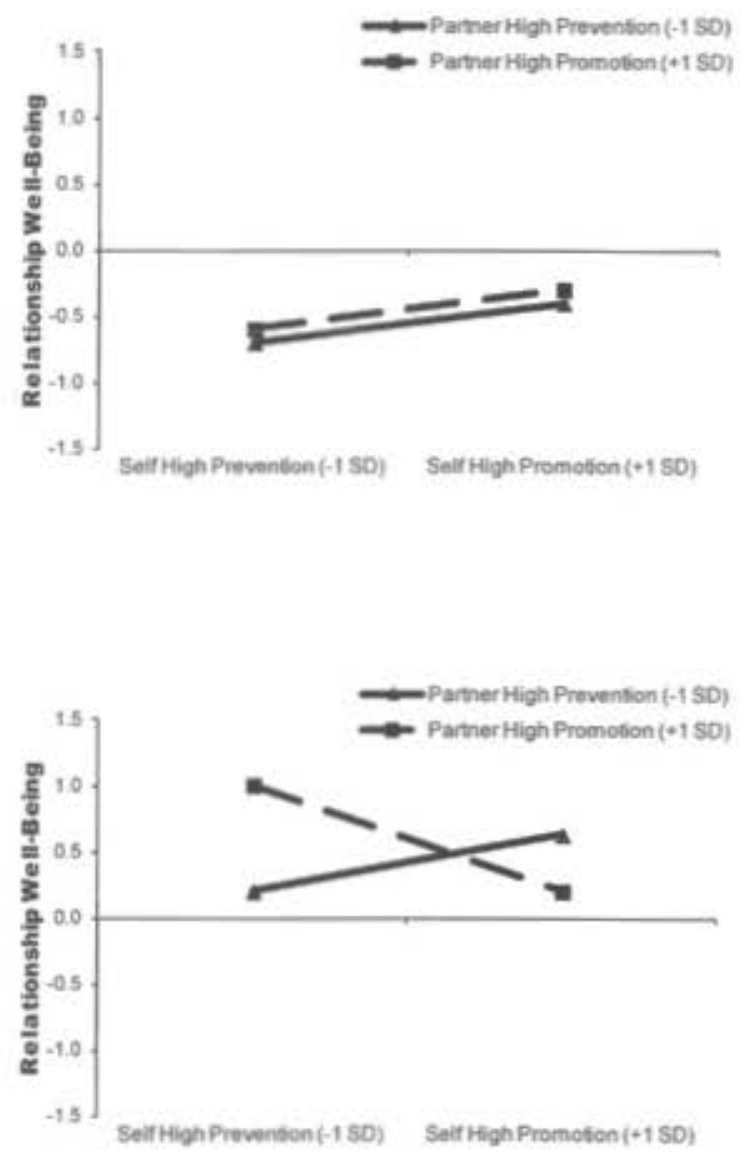

FICURE 2. The efiect of seli-regulatory focus $x$ partner regulatory focus on relationship wellbeing for relationships low in perceived self-other overlap (-1 SD; Panel A) vs. high in perceived self-other overlap $(+1$ SD, Panel B) in Study 2.

ous research (Fitzsimons \& Finkel, 2011; Plaks \& Higgins, 2000; Wegner, Erber, \& Raymond, 1991), and such specialization has been directly shown to be an important component in complementarity effects involving interaction partners' regulatory focus (Bohns \& Higgins, 2011). However, in the current research, we did not test this mechanism directly by asking about goals that can be "divided and conquered." Thus, one plausible explanation for our findings is that a relationship partner with a complementary regulatory focus orientation presents an opportunity for self-expansion when that relationship partner is included in one's own self-concept (Aron et al., 2004). We believe these two explanations-role specialization, and self-expansion-may operate in concert. A relationship partner with a complementary strategic preference may expand one's strategic repertoire, while simultaneously allowing oneself to adopt a role that "feels right" in the relationship.

In addition, while we originally theorized that mismatches in regulatory focus orientation might present challenges and therefore decrease relationship well-being for couples low in goal congruence, we did not in fact find a detrimental effect of complementarity under such conditions. This may be because individuals in 
relationships with low goal congruence do not need to coordinate the pursuit of joint goals with their partners. They may instead create regulatory fit by pursuing their own individual goals in their preferred strategic manner.

Given the large amount of previous support for the positive effect similarity can have on attraction and relationship well-being (Berscheid, 1985; Byrne, 1971), our finding that complementarity may also have relationship benefits under certain circumstances is noteworthy. Most previous research on interpersonal attraction and close relationships has focused on factors related to interpersonal agreement, such as attitudes and values, rather than interpersonal coordination (Rusbult \& Van Lange, 2003). However, our findings suggest that similarity and complementarity may each be beneficial within a restricted range of contexts: similarity may be particularly advantageous for establishing agreement on joint goals and avoiding conflict, while complementarity may be advantageous in situations where two individuals are already in agreement and are now concerned with interpersonal coordination and goal pursuit.

The broader self-regulatory framework we have provided for interpreting the current results is also consistent with previous findings. The domain in which complementarity effects have been most reliably demonstrated is dominance-

Au: Add to submissiveness (Dreyer \& Horowitz, 1997). Tiedens \& Fragale, 2003). Importantly, whereas complementary dominance orientations have been observed to increase liking and satisfaction for dyads and couples working on joint tasks with a clear common purpose, they do not have these same effects when dyads or couples simply engage in unstructured tasks (Moskowitz, Ho, \&Turcotte-Tremblay, 2007). This overall pattern of results supports our argument that complementarity is specifically beneficial for interpersonal coordination when two individuals exhibit high levels of goal congruence; the benefits of dominance complementarity seem only to emerge in conditions where two people are in agreement regarding their goals.

\section{CONCLUSION}

The present studies extend previous research on the task-related advantages of having a mix of self-regulatory strategies available during joint goal pursuit to include additional relationship benefits of complementary goal-pursuit strategies. We found that complementary self-regulatory orientations predicted greater relationship well-being specifically for couples with higher goal congruence. We theorize that under these circumstances complementary strategic preferences allow for a division of labor that allows each member of the couple to take on his or her preferred strategic role during joint goal pursuit, leading to greater overall satisfaction with the relationship. 


\section{REFERENCES}

Agnew, C. R., Van Lange, P. A. M., Rusbult, C. E., \& Langston, C. A. (1998). Cognitive interdependence: Commitment and the mental representation of close relationships. Journal of Personality and Sacial Psychology, 74, 939-954.

Aron, A., Aron, E. N., \& Smollan, D. (1992). Inclusion of Other in the Self Scale (IOS) and the structure of interpersonal closeness. Journat of Personality and Social Psychology, 63, 596-612.

Aron, A., Mclaughlin-Volpe, T., Mashek, D., Lewandowski, G., Wright, S. C., \& Aron, E. N. (2004). Including others in the self. Europarn Review of Social Psychology. 15. 101-132.

Berscheid, E. (1985). Interpersonal attraction. In G. Lindzey \& E. Aronson (Eds.). Handbook of social psychology (3rd ed., pp. 413-484). New York: Random House.

Bogacz, R, Brown, E., Moehlis, J., Holmes, P., \& Cohen, J. D. (2006). The physics of optimal decision making: A formal analysis of models of performance in two-alternative forced-choice tasks. Psychological Review, 113, 700-765.

Bohns, V. K., \& Higgins, E. T. (2011). Liking the same things, but doing things differently: Outcome versus strategic compatibility in partner preferences for joint tasks. Social Cognition, 29, 497-527.

Byme, D. (1971). The attraction paradigm. New York: Academic.

Cesario, J, Grant, H., \& Higgins, E. T. (2004). Regulatory fit and perstaasion: Transfer from "feeling right." lournal of Personality and Social Psychology, 86, 388-404.

A $U: \longrightarrow \quad \longrightarrow(A U)$ : Please add ref for Dryer \& Horowitz (1997) per citation on pp. 14 \& $18>>$

Finkel, E. J., Campbell, W. K., Brunell, A. B. Dalton, A. N., Chartrand, T. L., \& Scarbeck, S. J. (2006). High-maintenance interaction: Inefficient social coordination impairs self-regulation. Journal of Personality and Social Psycholory, 91, 456-475.

Fishbach, A., \& Ferguson, M. (2007). The goal construct in social psychology, In A. W. Kruglanski \& E. T. Higgins (Eds.) Social psychology: Handbook of hasic principles (pp. 490-515). New York Guilford.
Fitzsimons, G. M., \& Finkel, E. J. (2011), Outsourcing self-regulation. Psychological Science, 22, 369-375.

Fletcher, G. O., Simpson, J. A., \& Thomas, G. (2000). The measurement of perceived relationship quality components: A confirmatory factor analytic approach. Personality and Social Psychology Bulletin, 26, 340-354.

Fraley, R. C., Waller, N. G. \& Brenner, K. A. (2000). An item response theory analysis of self-report measures of adult attachment. Journal of Personality and Social Psychology, 78, 350-365.

Freitas, A. L, \& Higgins, E. T. (2002). Enjoying goal-directed action: The role of regulatory fit. Psychological Science, 13, 1-6.

Gable, S. L. (2006). Approach and avoidance social motives and goals. Journal of Personality, 74, 175-222.

Gere, J., Schimmack, U., Pinkus, R. T., \& Lockwood, P. (2011). The effects of romantic partners' goal congruence on alfective well-being. Journal of Research in Personality, 45, 549-559.

Hamilton, R., Vohs, K., Sellier, A. L. \& Meyvis, T. (2010). Being of two minds: Switching mindsets cxhausts self-regulatory resources. Unpublished manuscript, Emory University.

Hendrick, S. S., Hendrick, C., \& Adlex, N. L (1988). Romantic relationships: Love, satisfaction, and staying together. Journal of Personality and Social Psychology. 54, $980-988$.

Higgins, E. T. (1997). Beyond pleasure and pain. American Psychologist, 52, 12801300.

Higgins, E. T. (2000). Making a good decision: Value from fit. American Psychologist, 55. 1217-1230.

Higgins, E. T. (2008). Culture and personality: Variability across universal motives as the missing link. Sociall and Personality Psychology Compass, 2, 608-634.

Higgins, E. T., Friedman, R. S., Harlow, R. E., Idson, L. C., Ayduk, O. N., \& Taylor, A. (2001). Achievement orientations from subjective histories of success: Promotion pride versus prevention pride. Eurepean Journal of Social Psychology, 31, 3-23. 
Higgins, E. T., Idson, L., Freitas, A., Spiegel, S. \& Molden, D. (2003). Transfer of value from fit. Journal of Personality and Social Psychology, 84, 1140-1153.

Higgins, E. T., Pierro, A., \& Kruglanski, A. W. (2007). Re-thinking culture and personality: How self-regulatory universals create cross-cultural differences. In $\mathbf{R}$. M. Sorrentino (Ed.), Handbook of motiontion and cognition within and across cultures. New York: Guilford.

Hong, J., \& Lee, A. Y. (2008). Be fit and be strong: Mastering self-regulation through regulatory fit. Journal of Consumer Research, 34, 682-695.

Impett, E. A., Strachman, A., Finkel, E. J., \& Gable, S. L. (2008). Maintaining sexual desire in intimate relationships: The importance of approach goals. Journal of Personality and Social Psychology, 94, 808-823.

Kenny, D. A., Kashy, D. A., \& Bolger, N. (1998). Data analysis in social psychology. In D. Gilbert, S. Fiske, \& G. Lindzey (Eds.), The handbook of social psychology, Vol. 1 (pp. 233-265). Boston: McGraw-Hill,

Mauro, R., Pierro, A., Mannetti, L., Higgins, E. T., \& Kruglanski, A. W. (2009). The perfect mix: Regulatory complementarity and the speed-accuracy balance in group performance, Psychological Science, 20, 681-685.

Mehrabian, A., \& Hines, M. (1978). A questionnaire measure of individual differences in dominance-submissiveness. Educational and Psychological Measurement, 38 , 479-484.

Molden, D. C. (2012). Motivated strategies for judgment: How preferences for particular judgment processes can affect judgment outcomes. Social and Personalify Psychology Compass, 6, 156-169.

Molden, D. C., Lee, A. Y., \& Higgins, E. T. (2008). Motivations for promotion and prevention. In J. Shah \& W. Gardner (Eds.), Handbook of motivation science (pp. 169-187). New York: Guilford.

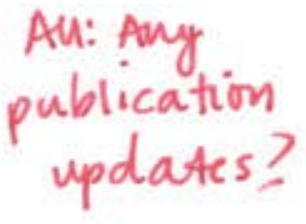

den, D. C., \& Winterheld, H. (in press). Motivations for promotion and prevention in close relationships. In J. Simpson \& L. Campbell (Eds.), Oxford handbook of close relationships. New York: Cambridge University Press.

Moskowitz, D., Ho, M. R., \&Turcotte-Tremblay, A. (2007). Contextual influences on interpersonal complementarity. Personality and Social Psychology Bulletin, 33, 1051-1063.

Moskowitz, D. S., \& Cote, S. (1995). Do interpersonal traits predict affect? A comparison of three models. Journal of Personality and Social Psychology, 69, 915-924.

Murray, S. L., Holmes, J. G., \& Griffin, D. W. (2000). Self-esteem and the quest for felt security: How perceived regard regulates attachment processes. Journal of Personality and Social Psychology, 78, 478498.

Plaks, J., \& Higgins, E. T. (2000). Pragmatic use of stereotyping in teamwork: Social loafing and compensation as a function of inferred partner-situation fit. Journal of Personality and Social Psychology, 79. 962-974.

Raudenbush, S. W., \& Bryk, A. S. (2002). Hierarchical linear models: Applications and data analysis methods. New York: Sage.

Rempel, J. K., Holmes, J. G., \& Zanna, M. P. (1985). Trust in close relationships, Journal of Personality and Social Psychology. 49, 95-112.

Rosenberg, M. (1965). Society and the adolescent self-image. Princeton, NJ: Princeton University Press.

Rusbult, C. E., Martz, J. M., \& Agnew, C. R. (1998). The investment model scale: Measuring commitment level, satisfaction level, quality of alternatives, and investment size. Personal Relationships, 5, 357-391.

Rusbult, C. E., \& Van Lange, P. M. (2003). Interdependence, interaction and relationships. Antmual Review of Psychology, 54, 351-375.

Spanier, G. (1976). Measuring dyadic adjustment: New scales for assessing the quality of marriage and similar dyads. Journal of Marringe and the Family, 38, 15-28.

Tiedens, L, \& Fragale, A. (2003). Power moves: Complementarity in dominant and submissive nonverbal behavior. Journal of Personality and Social Psychology, 84, 558-568.

Wegner, D. M., Erber, R., \& Raymond, P. (1991). Transactive memory in close relationships. Journal of Personality and Social Psychology, 61, 923-92. 


\section{Au: Any publication updates?}

prevention. In J. Shah \& W. Gardner (Eds.), Handbook of motivation science (pp. 169-187). New York: Guilford.

Molden, D. C., \& Winterheld, H. (in press). Motivations for promotion and prevention in close relationships. In J. Simpson \& L. Campbell (Eds.), Oxford handbook of clase relationships. New York: Cambridge University Press.

Moskowitz, D., Ho, M. R., \&Turcotte-Tremblay, A. (2007). Contextual influences on interpersonal complementarity. Personality and Social Psychology Bulletin, 33, 1051-1063.

Moskowitz, D. S., \& Cote, S. (1995). Do interpersonal traits predict affect? A comparison of three models. Journal of Personality and Social Psychology, 69, 915-924.

Murray, S. L., Holmes, J. G., \& Griffin, D. W. (2000). Self-esteem and the quest for felt security: How perceived regard regulates attachment processes. Journal of Personality and Social Psychology, 78, 478498.

Plaks, J., \& Higgins, E. T. (2000). Pragmatic use of stereotyping in teamwork: Social loafing and compensation as a function of inferred partner-situation fit. Journal of Personality and Social Psychology, 79, 962-974.

Raudenbush, S. W., \& Bryk, A. S. (2002). Hierarchical linear models: Applications and data analysis methods, New York: Sage.
Rempel, J. K., Holmes, J. G., \& Zanna, M. P. (1985). Trust in close relationships. Journal of Personality and Social Psychology. 49, 95-112.

Rosenberg, M. (1965). Society and the adolescent self-image. Princeton, NJ: Princeton University Press.

Rusbult, C. E., Martz, J. M. \& Agnew, C. R. (1998). The investment model scale: Measuring commitment level, satisfaction level, quality of alternatives, and investment size. Personal Relationships, 5, 357-391.

Rusbult, C. E., \& Van Lange, P. M. (2003). Interdependence, interaction and relationships. Anmual Review of Psychology, 54. 351-375.

Spanier, G. (1976). Measuring dyadic adjustment: New scales for assessing the quality of marriage and similar dyads. Journal of Marringe and the Family, 38, 15-28.

Tiedens, L., \& Fragale, A. (2003). Power moves: Complementarity in dominant and submissive nonverbal behavior. Journal of Personality and Social Psychology, 84, 558-568.

Wegner, D. M., Erber, R., \& Raymond, P. (1991). Transactive memory in close relationships. Journal of Personality and Social Psychology, 61, 923-92. 